\title{
Degree of Agility with an Ontology Based Application
}

\author{
Markku Salo ${ }^{1}$, Evangelos Markopoulos ${ }^{1}$, Hannu Vanharanta ${ }^{2}$, Jussi Kantola ${ }^{1}$ \\ ${ }^{1}$ University of Vaasa (UVA), Department of Production, \\ FI 65101, Vaasa, Finland \\ mkusalo@gmail.com,epm@empross.com,Jussi.Kantola@uva.fi \\ ${ }^{2}$ Tampere University of Technology (TUT), Industrial Management, \\ Pohjoisranta 11 A, P.O. Box 300, FI-28101 Pori, Finland \\ hannu.vanharanta@tut.fi
}

\begin{abstract}
Agility is a concept and practice with significant importance in managing projects and organizations, although it can also be very risky due to its degree of fuzziness if not properly defined. This research re-defines agility, emphasizes the need for ontologies for its management, and creates an application to measure the degree of agility inside an organization. In this research, various definitions of agility were gathered for the creation of ontology through a mind map revealing the characteristics of agility. As part of the Co-Evolute theory and methodology, the first agility ontology was developed as well as an application that evaluates the degree of agility in an organization. The application includes statements on which the respondents give opinions concerning the current and future desired states of agility and its importance in an evaluative way. The application has proven to operate well and extensive validation and verification of the tests runs will follow.
\end{abstract}

Keywords: Ontology $\cdot$ Agility $\cdot$ Software engineering $\cdot$ Fuzzy Logic $\cdot$ Strategic Management $\cdot$ Management

\section{$1 \quad$ Introduction}

When thinking and speaking about agility, one has to be cautious. Many believe that agility isa trendy concept, a tool for all cases, an easy way out that can be implemented anytime, anywhere, but that might not actually be appropriate.

The concept of responsiveness seems to be the most important characteristic of agility. Organizations are trying to be more flexible and dynamic in the face of our changing world. On the other hand, companies are looking closely at added value concepts so that they can really see that they are continuously serving their customers. Agility can also be described with other adjectives like 'adaptability', 'customercompliant', 'flexible', 'responsive' and even 'yielding'. For agility to be conceived properly it is important to understand that the world and business, any business, is agile in many ways and that all the people inside the organization understand these different dimensions of agility in practice. Managers in particular, who are called up onto apply agility, must understand that agility starts from people and ends with inno- 
vative new management practices, solutions, products, and services for the organization and their customers. However, in some cases, making changes too quickly towards obtaining agility in management and leadership may be too risky.

To reduce the misconception of the term agility, it is important to re-define it using an ontology that can cover the areas and limits of the term in a specific environment. Ontology originally derives from philosophy and refers to the science of being. Recently, the term ontology has also been used in information technology, where it is a specification of a conceptualization. For this case study, we have created an ontology application and tested with student test subjects how organizations understand agility in companies. This paper views agility primarily from the ontology point of view for its utilization and application in business and teaching approaches, methods, and practices.

\section{Defining Agility}

The term agility has become very popular and trendy over the last two decades in almost all types of business and engineering activities, operations, and strategies. What is interesting is the fact that today's meaning of agility differs significantly from the dictionary definitions and the ones used prior to its adoption by the software engineering industry.

By definition agility means "being gently rolling, light, flexible, witty and nimble. It can be contrasted to rigidity."In practice, the term has a totally different meaning, as it stands for flexibility and adjustability. The agile concept became popular through the software engineering discipline and communities, as a solution to bypass bureaucratic complexity in the software development efforts imposed by strict software development processes, tools, and structures [1].

The problem that agility aimed to solve was quite clear but slightly contradictory. On the one hand, software development needed structured methodologies and a process to assure the engineering quality of the software produced, but on the other hand, technology constraints (continuously changing), client constraints (unstable requirements), project constraints (schedule and budget limitations) were considered obstacles in developing software within budget, on time, and with quality [7].The challenge was to bypass bureaucracy in software development processes and standards without being accused of development anarchy. To solve this challenge, the agile concept was invented, or reinvented to be more precise. The logic behind agile software development is to adjust the software development best practices based on the project constraints, environment, goals, and objectives. Thus, software development on smallsized projects could avoid, for example, long design, testing, and documentation processes. On large projects, the processes could be adjusted accordingly. On critical projects, the processes could be strengthened with additional ones in order to reach the critical requirements and conditions. The methodology was that there is no methodology, only adjustability and flexibility on the methodology towards reaching the desired project goal[8]. Therefore, agility became the Lego-type adjustment of the software development process. The results of applying agility in software development were very successful and all parties involved were satisfied, as software was 
developed with less process overhead for the engineers and much faster for the clients.

Agility, however, is very difficult to design and very risky to apply. Reducing the number of processes from a methodology requires high capability and maturity from those who attempt to select which processes are needed, which are to be removed, and which are to be changed in order to achieve agility. The same applies in management, as acting outside the box to bypass a problem requires significant expertise in order to make the right moves [9].

In software engineering, many agile methodologies have been developed over the last two decades, some of which were successful and others less successful [10]. The Ariadne Methodology, by EMPROSS Strategic IT Consultants, is one of the first agile software engineering and project management methodologies [11]. It was developed based on the agile Lego 'build it yourself' concept according to project constraints. The ARIADNE set of processes has made the methodology compatible with 108 international project management and engineering methodologies, while it supports more than 15 different software development types such as waterfall, spiral, incremental, rapid prototyping, etc.[12] (See Fig. 1).

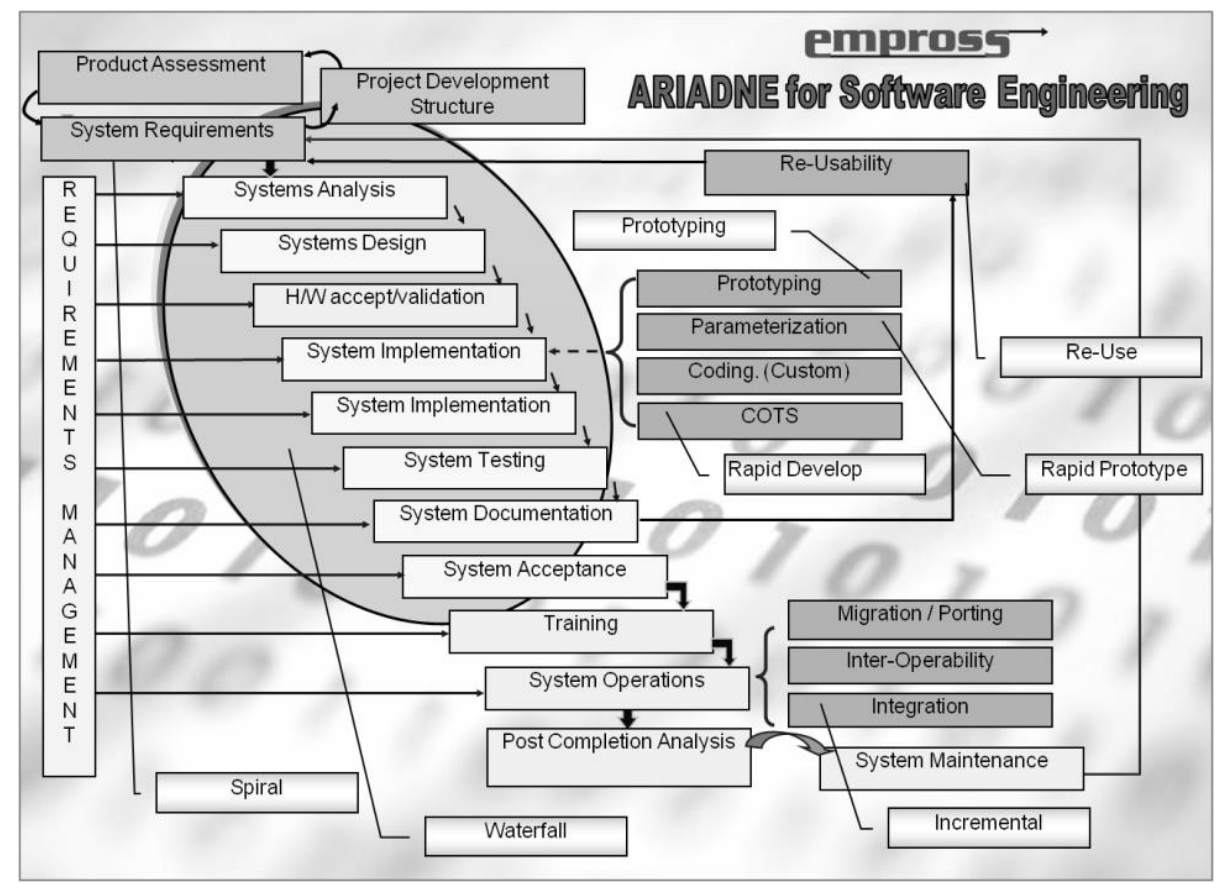

Fig 1. Methodological Approaches Supported by the ARIADNE Agile Software Engineering Methodology

Agile processes are not for everyone to follow and for only the best to design. They provide significant flexibility that can be critical when needed, but require tremendous 
expertise and discipline in the area in which they are being practiced. Agility can be a blessing but also a curse unless its consequences are deeply understood.

\section{Defining Ontology}

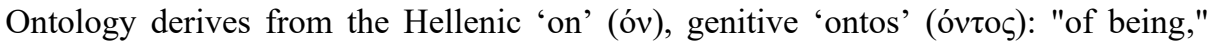
neuter participle of 'eine' (cíval): "to be," and 'logia' ( $\lambda$ o jí $\alpha)$ : science, study, theory. Based on the above definition of the term 'ontology,' it is obvious that ontologies are live and not static entities. They contain elements that have identities that affect and are affected by the environment they are used for and from [13].

The Stanford Encyclopedia of Philosophy [6] divides ontology into two different categories: firstly, ontology is the study of what there is, and secondly, it is the study of what is involved in settling questions about what there is in general. In the first case, we may ask if there is a God or not. According to Effingham [3], ontologists split things into two categories, i.e. the abstract and the concrete. Osterwalder[14] has studied business model on tologies and has developed practical ontologies through a theoretical approach. However, his approach is derived from an ICT approach; which also shows that ontologies in practical life are mostly used in information technology, business process modeling, and related activities.

Dietz [2] has studied enterprise ontology from his ICT background and point of view. In his mind, there has to be a conceptual model that is coherent, comprehensive, consistent, and concise. This model is an ontological model. He takes the example of the World Wide Web, which serves to provide a common basis for common understanding on some area of interest among a community of people.Vanharanta and Kantola[15] have taken some steps towards more practical approaches in ontology, although in many of their approaches there is an application in thebackground.

\section{$4 \quad$ Agility in Creating Ontologies}

Even though agility in ontologies can be considered their natural behavior, it is often hard to see this dimension when using them and much more when creating them. To enable agility in the creation of ontologies, one must understand the relationship of the elements that compose an ontology. All ontologies have passive and active elements that define a microcosm of activities, operations, and goals. This microcosm affects and is affected by other ontologies, based on the way they interact. Therefore well-designed ontologies are those that can be used the best and the most, meaning that they must be agile in order to achieve the desired flexibility and adjustability. Furthermore, the elements in an ontology can also be characterized as the imports and exports of information in the ontology. They are the elements that collect the information to be processed in the ontology and the elements that export information after being processed in the ontology. Figure 2 presents the elements of an agile ontology. The challenge in the creation of agile ontologies can be seen as a double one. First, it is important to properly identify the ontology elements and their relationships in order for the ontology to be agile, i.e., to be used with flexibility and adjustability on the maximum number of occasions. The second challenge is not actually based on the 
ontology itself but for the designer of the ontology to use it properly in the design of processes, systems, methods, and practices. Having a great tool does not make it great unless it is also used well. Besides the proper definition of the identities of the ontology elements towards achieving agility, the taxonomy of the elements also has a great significance for agility. An ontology can be designed to include sub-ontologies, which are actual taxonomies of the ontology elements. This breakdown of the ontology elements into taxonomies can define the range of usage of the ontology and greatly affect its behavioral identities.

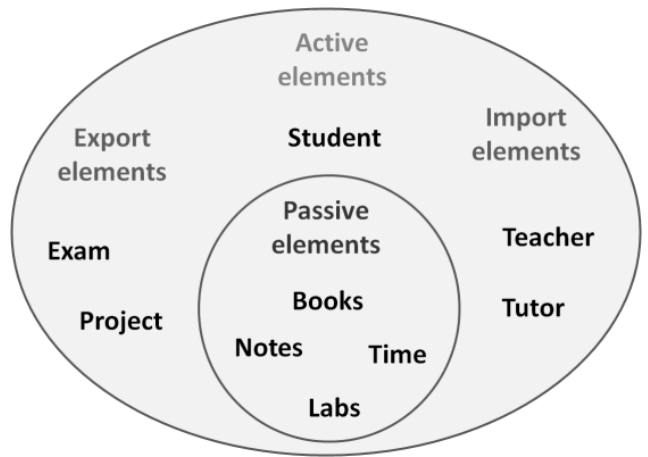

Fig 2.Agile 'Teach' ontology with relationships between elements

The ontology 'teach' and the ontology 'learn' for example seem to have a direct link and meaning, but agility is achieved in the ways teaching is done and the ways learning is achieved. The degree of agility is based on the number of ways that such combinations can be satisfied. One way to achieve this is if the two ontologies can be viewed as taxonomies of a greater 'Teach-Learn' ontology that defines variations of teaching and learning within the ontology (Fig. 3). These variations define agility in the terms in the use of the ontology.

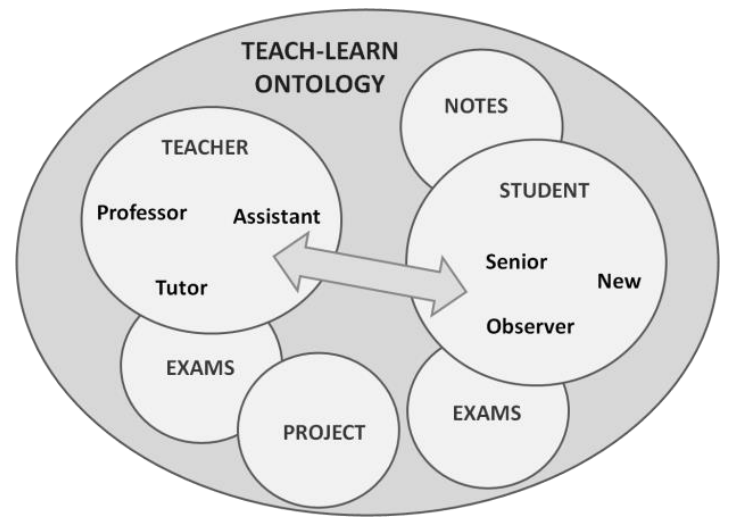

Fig. 3.Taxonomies within ontologies for maximum ontology agility

Agility is not a practice, a method, a process, or a trend, but an art of understanding real work and trying to satisfy its continuous changing needs. Agile ontologies are very important towards developing agile processes, methods, and practices. The agili- 
ty resides in the ontology and not in the methodology, which is composed of ontologies that drive and support the process and practices of the methodology. Once such a view can be conceived, then obtaining agility can be very easy, but it is not easy to think easy.

\section{$5 \quad$ Ontology Application}

An ontology application exists on the Evolute platform [4].The platform has various other applications to assess and follow up the development of an organization within its various operations and functions. The test application is called Catenary.

The Evolute approach follows a modular process involving individuals and stakeholders, where their perception and understanding of organizational resources are sought and collected with the help of statements, one by one. The Evolute system $[4],[5]$ is a platform that computes and visualizes the meaning of the knowledge input collected from stakeholders. The computing in the Evolute system is based on softcomputing methods and algorithms in order to cope with the imprecision and uncertainty embedded in natural language and human knowledge inputs. Management uses the computed current and future meaning of organizational resources to make a development analysis of the organization. The analysis can be made of the whole group and sub-groups. Stakeholders can be involved in this management step, according to the modular process.

\section{Research Study}

A research study was conducted in January - February 2016 with 19 persons, representing both Tampere University of Technology Pori unit students and various Finnish companies. The researchers created ontology statements that were entered into the application. The number of statements was about 110, varying from the understanding of the term agility to its implementation and control. There were several subcategories as well.

Since this was just the first test of the application, the number of participants was limited. Hence it is difficult to draw final scientific conclusions from this study alone. More research is required to validate and verify the results of this kind of study. An example of how the statements are organized is shown in Table 1.

Table 1.Example of Agility Ontology Statements

\begin{tabular}{|c|c|c|c|c|}
\hline $\begin{array}{l}\text { High Level } \\
\text { Concept }\end{array}$ & $\begin{array}{l}\text { Sub- } \\
\text { Concept }\end{array}$ & Indicators & MIN & MAX \\
\hline \multirow[t]{5}{*}{$\begin{array}{l}\text { General } \\
\text { concept }\end{array}$} & $\begin{array}{l}\text { Agility } \\
\text { awareness }\end{array}$ & - I understand the term agility & not at all & completely \\
\hline & & $\begin{array}{l}\text { - Most people in our organization under- } \\
\text { stand the term agility }\end{array}$ & not at all & completely \\
\hline & & - Our organization has to be agile & not at all & definitely \\
\hline & & $\begin{array}{l}\text { - We have no need for agility in our } \\
\text { organization }\end{array}$ & not at all & definitely \\
\hline & & - Our company is "fast" & not at all & absolutely \\
\hline
\end{tabular}




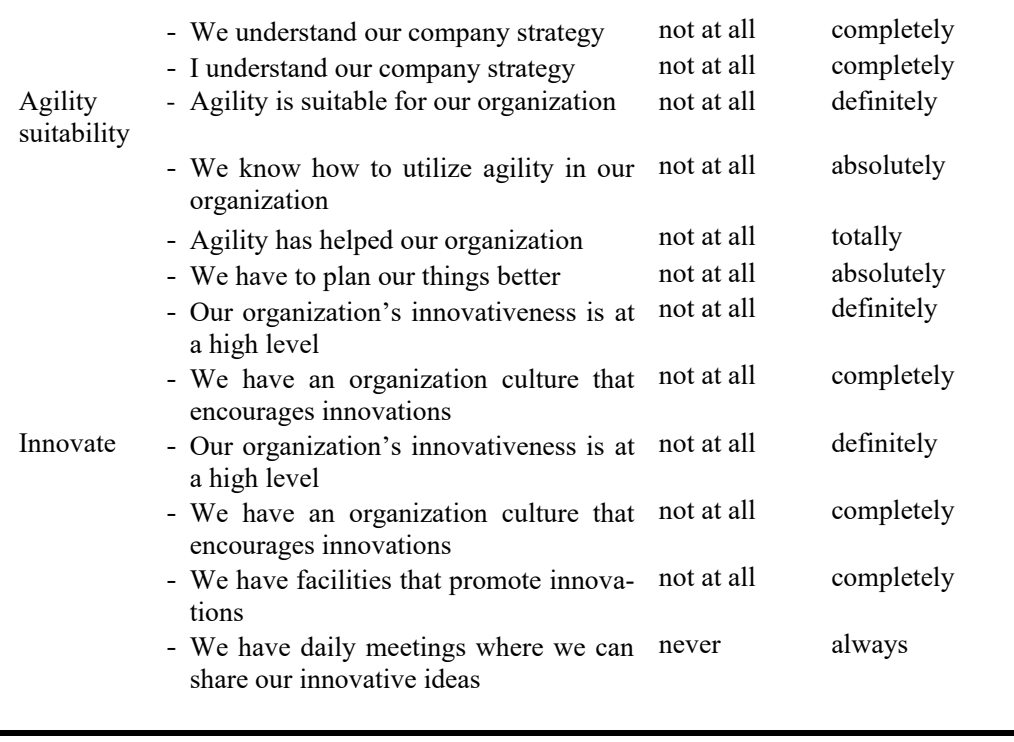

\section{$7 \quad$ Results}

The Catenary application itself worked perfectly as expected. The results reflect the status of the respondents' organizations and are taken as such. Each organization has to continue its internal thinking and development based on the achieved results. They show, slightly surprisingly, that the investigation of problems category is in the best state within the organizations, whilst the rest are more or less at the same level, with general principles and rules being slightly higher than tools and general concept. The aggregate results can be seen in Figure 4 and detailed results by topic in Figure 5, while Figure 4 shows the summary by category.

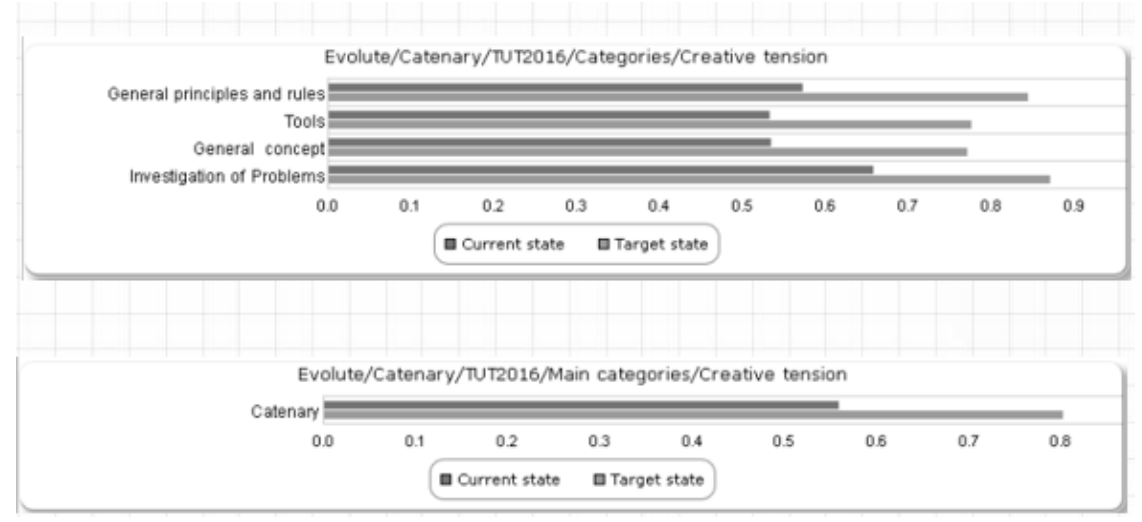

Fig.4 Summary of agility study results by main category

In Figure 5 the individual statements have been sorted by their "ranking." 


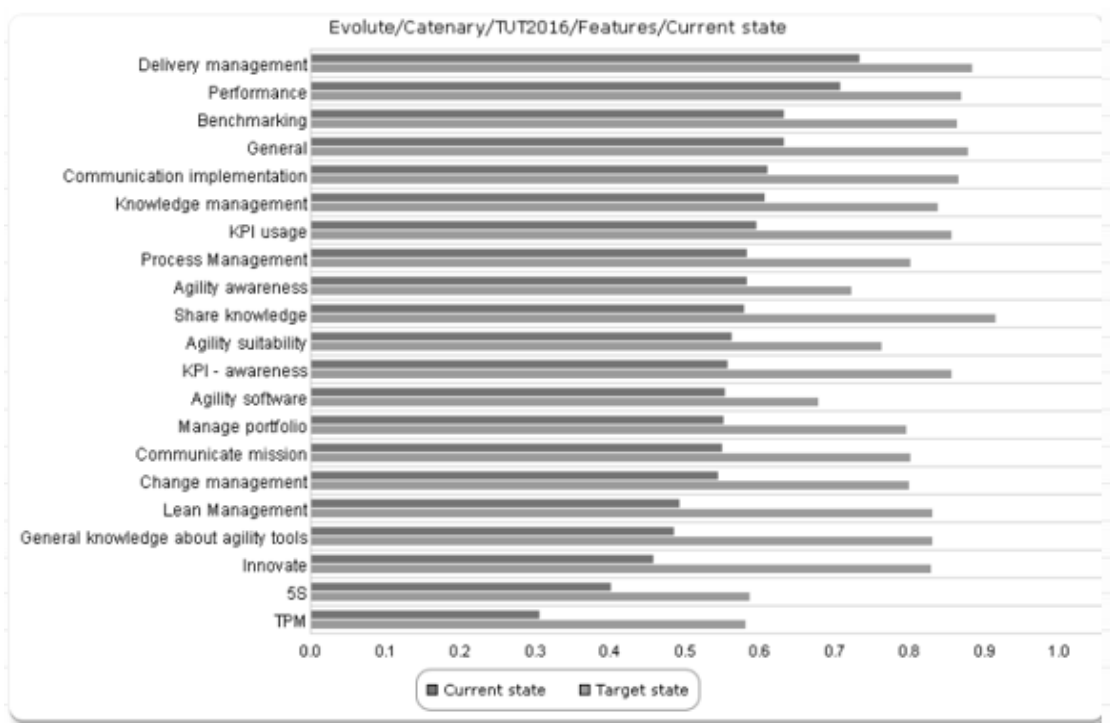

Fig 5.Details of agility study results by topic

The current state seems to be best in delivery management, performance, and benchmarking. The opposite is true for instance for TPM, 5S, innovativeness, etc.One cannot say whether the results are right or wrong but they show a direction for the company to develop its activities. In Figure 6 the individual statements have been sorted by their "ranking" according to the future state.

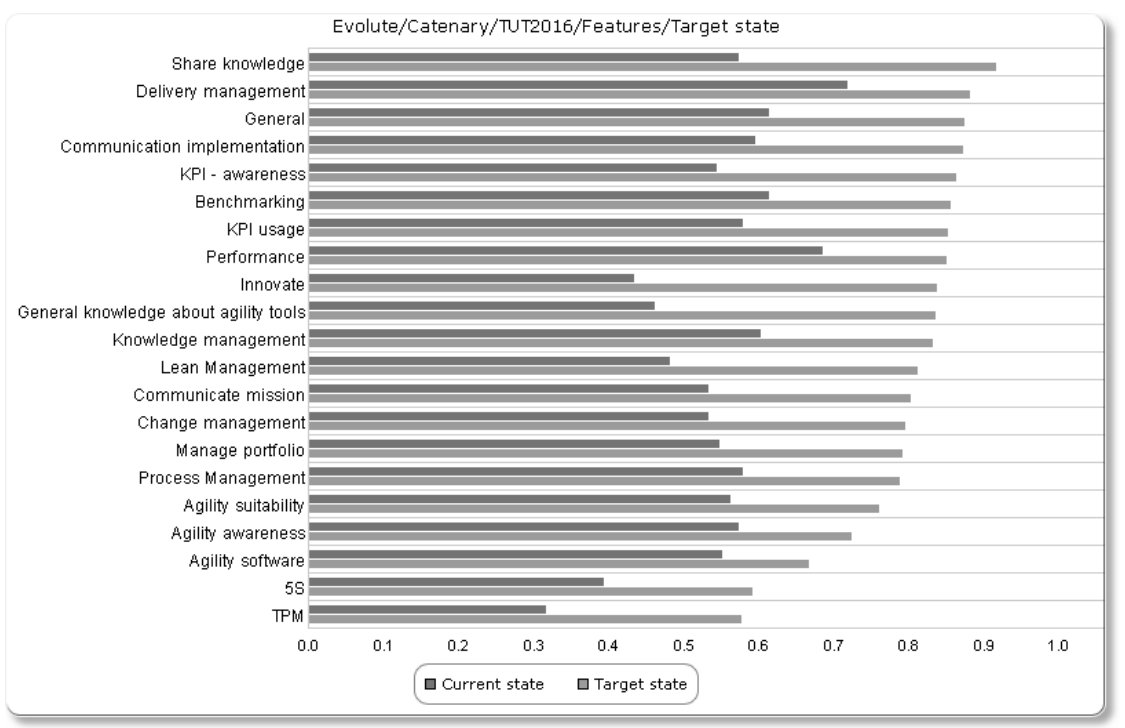

Fig 6.Test results sorted by future state 
The most important point in Figure 6 is to share knowledge. It is also possible to obtain an index from the system describing the ratio of the future to current state. This index is called the Evolute index. From the data we can get the following Figure 7 where the Evolute index test results are shown.

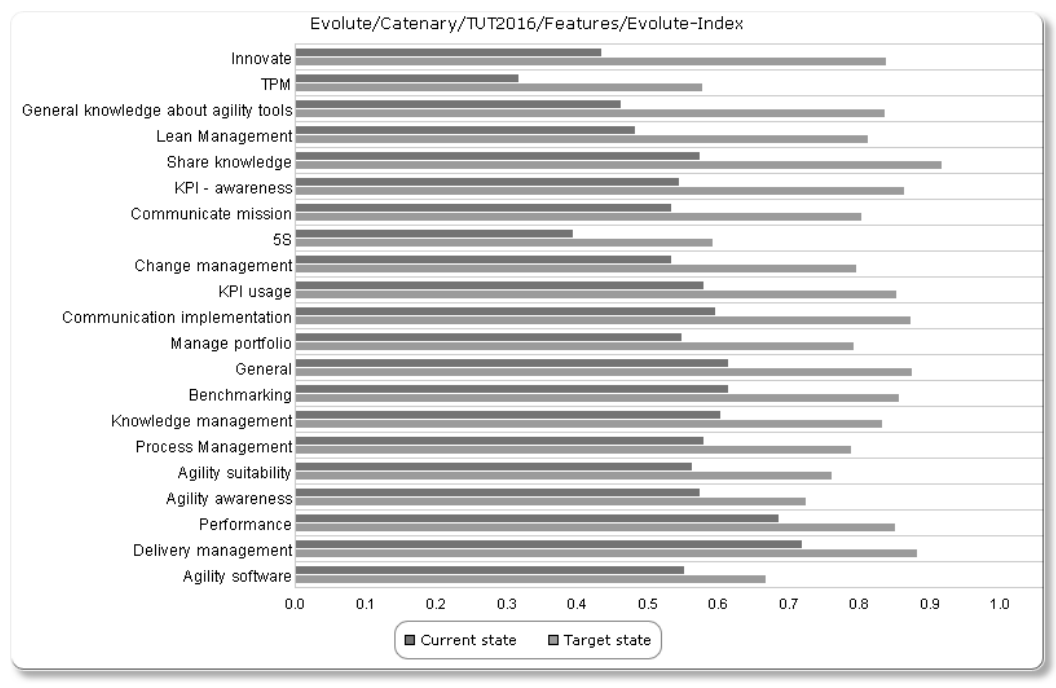

Fig 7.Test results with the Evolute index

From the results we can see that the highest index is in innovation issues, followed by TPM, and after that general knowledge about agility tools. In this index, the lowest concepts are agility software and delivery management.

The statements in the application should be further developed. However, in this application, in contrast for instance to the applications that are closer to psychological tests, it is fair to say that there is no need to compare the results with similar applications. On the other hand, we do not know of any similar practical agility application currently available on the market.

\section{Discussion and Conclusions}

Ontology is not very common in business, apart from applications for the information and communications technology sector, which invented the concept. Even to understand what ontology means is very difficult for most people as it integrates a philosophical dimension. Philosophy is a difficult subject and most business people understand very little of it. Hence easy methods need to be created and taught to give the necessary help for understanding such concepts. Tools that have been developed by EMPROSS or Evolute LLC support this thinking in the agility area.

The agility created in the plans and strategies of many businesses obliges managers to be very careful when implementing it. Agility can suit some businesses, but not necessarily all of them. For instance, should governments be agile or not? How about 
many heavy industries- can they be agile? and to what degree? In our opinion, agility is well suited for the software business, and electronics-related businesses like mobile phones, electronic components, computers, etc. where innovation cannot be controlled with a static structure and non-flexible management and leadership.

The agility / ontology tool developed during this research is very practical and can be used in any organization. It clearly shows the status of agility in an organization and its development needs. We can find many similar areas, functions, and disciplines in organizations to develop ontologies. Developing an ontology by using the application is not a very complicated task and can be used by everyone. To achieve the effective development of such applications, a minimum set of research statements is required. There are nowadays so many questionnaires that many organizations and individuals have to participate in that there is a common dissatisfaction towards large questionnaires and repeated processes.

Time will show whether ontologies will be used more in practical business life. One can assume that they will be used more and more when developing information systems and business processes for managing innovation effectively, but we have to think more broadly, as innovation does not only exist in the technology sector. Ontologies can help this thinking, as they provide all the potential needed to support agile thinking in organizations with processes and tools.

\section{References}

1. Beck, Kent: et al. (2001), "Manifesto for Agile Software Development. Agile Alliance. Retrieved 14 June 2010.Manifesto for Agile Software Development Available at: http://agilemanifesto.org/. (Accessed 14 December 2015).

2. Dietz, J.L.G., Enterprise Ontology, Springer-Verlag, Berlin, (2006)

3. Effingham, N., An Introduction to Ontology, Polity, Press, Malden, MA, USA, (2013)

4. https://www.evolute.com, March, (2016)

5. Kantola, J. Organizational Resource Management: Theories, Methodologies, and Applications, CRC Press, 138 p. (11/2015)

6. http://plato.stanford.edu/index.html, March, (2016)

7. Markopoulos E., Panayiotopoulos J-C., (2008) 'A Project Management Methodology Selection Approach based on Practical Project and Organizational Constraints', WSEAS Transactions on Computers, Issue 8, Vol. 4, pp. 934-942, August 2005.

8. Markopoulos E., Bilbao J., L., Stoilov T., Vos T., Reschwamm K., (2008a) 'Project Management Stage Mutations within Agile Methodological Framework Process Transformations' WSEAS '05 International CSCC Conference, 12-16 April, 2008, Beijing, China.

9. Markopoulos E., (2008b), 'ICT Process Development and Evolution Models and the First Financial Bank of Montenegro Case'. The Bankar - Montenegro Bank Association Journal. Issue 1, Volume 1, May 2008.

10. Markopoulos E., Bilbao J., L., (2006), 'An evaluation, Correlation and Consolidation of Information Technology Project Management Processes', 1st International Conference on Engineering and Mathematics, Bilbao, Spain, July 2006.

11. EMPROSS (2002a). The Ariadne Methodology. Available at: http://www.empross.com/en/the_ARIADNE_Methodology. (Accessed 14 December 2015).

12. EMPROSS (2002b). The Ariadne Methodology. Available at: http://www.empross.com/en/methodological_approaches. (Accessed 14 December 2015). 
13. Oberle, D., Guarino, N., \& Staab, S. (2009), 'What is an ontology?'. In: "Handbook on Ontologies, International Handbooks 1 on Information Systems, Springer-Verlag, Berlin Heidelberg, (2009)

14. Osterwalder, A., The Business Model Ontology - a Proposition in a design Science Approach, l'Ecole des Hautes Etudes Commerciales de l'Universite de Lausanne, Switzerland, (2004)

15. Vanharanta, H., Kantola, J., Strategy needs structure: Structure needs ontologies - Dynamic ontologies carry meanings. In:"Proceedings of the International Conference on Knowledge Management and Information Sharing”, Liu, K. \& Filipe, J. (eds.). Portugal: SCITEPRESS - Science and Technology Publications, p. 261-264 (International Conference on Knowledge Management and Information Sharing) Barcelona, Spain, (4-7 October, 2012). 